\title{
Author Correction: Highly efficient reversible protonic ceramic electrochemical cells for power generation and fuel production
}

Chuancheng Duan, Robert Kee, Huayang Zhu, Neal Sullivan, Liangzhu Zhu, Liuzhen Bian, Dylan Jennings and Ryan O'Hayre

Correction to: Nature Energy https://doi.org/10.1038/s41560-019-0333-2, published online 11 March 2019.

In the version of this Article originally published, in Fig. $3 b$ the wrong experimental data, the concentration of hydrogen (vol. \%), were plotted for the black and blue curves, instead of the hydrogen production rate. In addition, in the legend, in the label for the blue curve ' $500{ }^{\circ} \mathrm{C}$ ' should have been ' $550^{\circ} \mathrm{C}$ '. Furthermore, in Fig. $3 \mathrm{~b}, \mathrm{f}$, the units on the $y$ axis " $\mathrm{ml}^{-1} \mathrm{~min}^{-1} \mathrm{~cm}^{-2}$ " were incorrect and should have been " $\mathrm{ml} \mathrm{min} \mathrm{m}^{-1} \mathrm{~cm}^{-2}$ ". The original and corrected Fig. $3 \mathrm{~b}$ are shown below. These errors have been corrected in all versions of the Article.


Fig. 3b | Original and corrected.

Published online: 22 July 2020

https://doi.org/10.1038/s41560-020-0669-7

(c) The Author(s), under exclusive licence to Springer Nature Limited 2020 